\title{
Effects of two different protocols of oxytocin infusion for labor induction on obstetric outcomes: A cohort study ${ }^{*}$
}

\author{
Alessandro Ghidini", Diann Wohlleb, Victoria Korker, John C. Pezzullo, Sarah H. Poggi \\ Department of Obstetrics and Gynecology, Inova Alexandria Hospital, Alexandria, USA \\ Email: \#Alessandro.Ghidini@Inova.org
}

Received 25 February 2012; revised 20 March 2012; accepted 31 March 2012

\begin{abstract}
Objective: Concerns remain about the safety and efficacy of high dose and low dose protocols of oxytocin for labor induction. We have compared 2 regimens of oxytocin induction (low-dose vs high dose) on perinatal outcomes over a 1-year period. Study Design: Included were all women undergoing induction of labor at term with live singleton gestations. Cesarean delivery (CD) and a composite adverse neonatal outcome (5-min Apgar score < 7, umbilical artery $\mathbf{p H}<$ 7.10, or need for admission to NICU) were assessed using logistic regression analysis. Admission-to-delivery intervals was compared between the two groups by log-rank test. Results: A total of $\mathbf{5 4 4}$ women fulfilled the study criteria. The two groups were comparable for demographic and obstetric variables. There was no significant association between oxytocin regimen and rates of $C D(P=0.77)$ or adverse neonatal outcome $(P=0.99)$ even after controlling for confounders. The admission-to-delivery interval was significantly shorter for the high-dose group than for the low-dose group (median interval $=11.7$ vs 14.3 hours, respectively, $P=\mathbf{0 . 0 2 6}$ ). Conclusion: Use of a highdose protocol of oxytocin administration for induction of labor at term is associated with similar rates of cesarean section and adverse neonatal outcome as a low-dose protocol, but with an average of 2.5 hours shorter duration of labor.
\end{abstract}

Keywords: Induction of Labor; Term Pregnancy; Oxytocin Dosage; Cesarean Delivery; Adverse Neonatal Outcome

\section{INTRODUCTION}

Induction of labor is a common procedure, performed in over $20 \%$ of pregnancies [1]. Multiple protocols have

\footnotetext{
"Conflict of interest: the authors have no conflict of interest or any competing financial interest with the subject of this study.

"Corresponding author.
}

been proposed over the years for the use of oxytocin in the induction of labor. High- and low-dose protocols differ in initial dose, and timing or size of incremental increase. In general, low-dose oxytocin protocols entail a starting dose of $1-2 \mathrm{mU} / \mathrm{min}$ followed by incremental increases of 1 - $2 \mathrm{mU} / \mathrm{min}$ every 15 - $40 \mathrm{~min}$. High-dose protocols entail a starting dose of up to $6 \mathrm{mU} / \mathrm{min}$ followed by incremental increases of $3-6 \mathrm{mU} / \mathrm{min}$ every 15 - $40 \mathrm{~min}$. Unlike augmentation of labor, for which a recent systematic review found that high-dose oxytocin protocols are associated with a decrease in cesarean section and shortened labor compared with low-dose protocols, [2] there is controversial evidence on the effects of oxytocin protocols for induction of labor. The only randomized, double-blinded trial of low-dose versus highdose oxytocin for labor induction found that high-dose oxytocin was associated with a significant (approximately 2 hours) shortening of labor [3]. The American College of Obstetricians and Gynecologists does not recommend any specific protocol because of lack of evidence of benefit or risk of any one protocol over the others [1].

At Inova Alexandria Hospital (IAH), a suburban community hospital, there was traditionally a plethora of induction protocols with oxytocin, as any physician had his/her own preference. However, standardization of protocols for labor induction with oxytocin is desirable because it is a proven route to increased patient safety [4]. To this effect, in April, 2008 only 2 protocols of induction of labor with oxytocin were allowed in Labor and Delivery at IAH, modeled after the ranges quoted in the ACOG practice bulletin [1]: a low-dose protocol, in which the initial dose was $2 \mathrm{mU} / \mathrm{min}$ increased by $2 \mathrm{mU} / \mathrm{min}$ every $15 \mathrm{~min}$ up to a maximum of $36 \mathrm{mU} / \mathrm{min}$; and a high-dose protocol in which the initial dose was 4 $\mathrm{mU} / \mathrm{min}$, increased by $4 \mathrm{mU} / \mathrm{min}$ every $15 \mathrm{~min}$ up to a maximum dose of $36 \mathrm{mU} / \mathrm{min}$.

In the current study we have compared the 2 protocols over a 1-year period so as to determine the safety and efficacy of the 2 regimens in the management of induction of labor at term. 


\section{MATERIALS AND METHODS}

All women who underwent induction of labor at term from December 1, 2009 and November 30, 2010 were considered for inclusion in the study. Inclusion criteria were: singleton gestation with live fetus in cephalic presentation at a gestational age of 39.0 weeks or greater.

Excluded from the study were women with abnormal presentation, placenta previa, twins, active genital herpes, non reassuring fetal testing, history of cesarean section or uterine scar involving the endometrium, and those requiring oxytocin for labor augmentation rather than induction.

For both protocols, 30 units of synthetic oxytocin (Lyphomed, Fujisawa USA, Deerfield, IL) were diluted in $500 \mathrm{~mL}$ of Ringers solution and infused by an intravenous line piggybacked to a main intravenous line. Oxytocin infusion rate was controlled by continuous electronic infusion pump. Fetal heart rate and uterine contractions were continuously monitored electronically in all patients. The goal of induction was to achieve 3 to 5 uterine contractions in 10 minutes. Labor was defined as regular contractions with evidence of cervical change (dilatation or effacement). Amniotomy was performed at the discretion of the attending physician. Oxytocin was decreased to the previous dose in the presence of uterine tachysystole, defined as $>5$ contractions in 10 minutes for 20 minutes. Tachysystole associated with non-reassuring fetal heart rate tracing indicated discontinuation of oxytocin infusion and administration of a tocolytic (Terbutaline $0.25 \mathrm{mg}$ subcutaneously), in addition to implementation of fetal resuscitative measures (maternal left lateral decubitus, oxygen administration and increase in intravenous fluid rate). Management of labor and delivery was otherwise left to the managing obstetrician or midwife. Staining of amniotic fluid with meconium of any degree of intensity was recorded. Post-partum hemorrhage was defined as blood loss at delivery requiring blood transfusion, hysterectomy or uterine embolization by interventional radiology.

All pertinent information was entered by a staff nurse into a dedicated electronic record (Centricity Perinatal System, General Electric, Chicago, IL). Each perinatal record was assessed for consistency and completeness by the managing clinician at delivery. The study was approved by the Institutional Review Board committee (protocol ${ }^{\#} 10.150$ ).

Statistical analysis: the 2 groups (low-dose vs highdose of oxytocin) were compared for demographic and obstetric variables using Fisher's exact test and Chisquare test for categorical variables, and t test or oneway analysis of variance for continuous variables (SAS software version 8.2, SAS Institute Inc., Cary, NC). Main outcome measures were rate of cesarean delivery and occurrence of adverse neonatal outcome, defined as admission to the NICU, 5-minute Apgar score below 7, or umbilical artery $\mathrm{pH}<7.10$. The 2 outcome measures were compared using logistic regression analysis to control for confounders. Total time in Labor and Delivery (interval from admission to delivery) was calculated and graphed as Kaplan-Meier survival curves (with censoring if a cesarean section was performed), and compared between the 2 groups by the log-rank test, and by Cox proportional hazards regression to control for confounders. A 2-tailed $\mathrm{P}$ value $<0.05$ or an odds ratio (OR) with $95 \%$ confidence interval (CI) not inclusive of the unity was considered statistically significant.

\section{RESULTS}

A total of 862 women underwent induction of labor during the study period. During the same period, a total of 3917 women delivered at IAH. Inclusion and exclusion criteria for the study were fulfilled by 544 women, of which 451 underwent induction of labor with the lowdose protocol and 93 with the high-dose protocol. Table $\mathbf{1}$ displays the demographic and obstetric characteristics of the study population. The 2 groups were similar for all the variables analyzed, with about $60 \%$ nulliparous women in both groups. Table 2 displays the indications for induction of labor. "Large for gestational age" was the only indication significantly different between the two oxytocin protocols but, as shown in Table 3, it did not reflect differences in fetal size according to actual birth weights.

Adverse neonatal events were observed in 9 cases (1.7\%), including 2 with 5 minute Apgar score below 7, 3 with umbilical artery $\mathrm{pH}<7.10$, and 8 admitted to the NICU (some neonates had more than 1 adverse event). When such cases were compared with those with a favorable neonatal outcome (Table 3), only multiparity and cesarean delivery were significantly different between the two groups. However, logistic regression analysis demonstrated that neither oxytocin protocol $(\mathrm{P}=0.99)$, nor any other individual variable was independently associated with adverse neonatal outcome (cesarean section: OR 3.4, 95\% CI 0.8 - 14.6, P = 0.10; multiparity: OR 0.2, 95\% CI 0.1 - 1.9, P = 0.17).

Cesarean delivery was required in $27 \%(149 / 544)$ of cases $(27.4 \%$ or $122 / 445$ of low-dose cases, and $27.3 \%$ or 27/99 of high-dose cases). Women delivered by cesarean section were more frequently nulliparous, had lower gestational age at delivery, required prostaglandin gel more frequently before induction of labor, had higher rates of meconium-stained amniotic fluid during labor and had higher rates of adverse neonatal outcome (Table 4). Logistic regression analysis demonstrated that odds of cesarean delivery were independently associated with multiparity (OR 0.16, 95\% CI $0.10-0.26$ ), gestational 
Table 1. Demographic and obstetric characteristics in relation to oxytocin protocol dose.

\begin{tabular}{|c|c|c|c|}
\hline & Low-dose $(n=451)$ & High-dose $(n=93)$ & P value \\
\hline Maternal age (years) & $29.7 \pm 5.8$ & $29.8 \pm 5.6$ & 0.82 \\
\hline Multiparity & $44 \%$ & $42 \%$ & 0.81 \\
\hline Gestational age (weeks) & $40.2 \pm 0.7$ & $40.2 \pm 0.7$ & 0.86 \\
\hline Epidural anesthesia during labor & $86 \%$ & $93 \%$ & 0.11 \\
\hline Artificial rupture of membranes & $72 \%$ & $80 \%$ & 0.10 \\
\hline Prostaglandin gel before oxytocin & $31 \%$ & $22 \%$ & 0.12 \\
\hline Hyperstimulation syndrome requiring tocolysis & $2 \%$ & 0 & 0.37 \\
\hline Meconium-stained amniotic fluid & $13 \%$ & $11 \%$ & 0.67 \\
\hline Cesarean delivery & $123(27 \%)$ & $26(30 \%)$ & \\
\hline For CPD & 70 & 17 & \\
\hline For failed induction & 23 & 4 & 0.90 \\
\hline For fetal distress & 27 & 5 & \\
\hline Other indications & 3 & 0 & \\
\hline Post-partum hemorrhage & 3 & 0 & 0.57 \\
\hline Birth weight (grams) & $3560 \pm 410$ & $3541 \pm 389$ & 0.72 \\
\hline Adverse neonatal events & $9(2 \%)$ & 0 & \\
\hline Neonatal death & 0 & 04 & \\
\hline Admission to the NICU & 8 & 0 & 0.18 \\
\hline Apgar score at $5 \mathrm{~min}<7$ & 2 & 0 & \\
\hline Umbilical artery $\mathrm{pH}<7.10$ & 3 & 0 & \\
\hline
\end{tabular}

Legend: CPD, cephalopelvic disproportion; NICU, neonatal intensive care unit.

Table 2. Indications for induction of labor in relation to oxytocin protocol dose.

\begin{tabular}{cccc}
\hline & Low-dose $(\mathrm{n}=451)$ & High-dose $(\mathrm{n}=93)$ & P value \\
\hline Post dates pregnancy & 241 & 51 & 0.80 \\
Oligohydramnios & 58 & 11 & 0.76 \\
Elective & 29 & 2 & 0.70 \\
Gestational diabetes/diabetes & 25 & 3 & 0.17 \\
Hypertensive complication of pregnancy & 22 & 8 & 0.49 \\
Large for gestational age & 12 & 3 & 0.006 \\
Premature rupture of membranes & 4 & 2 & 0.07 \\
Fetal growth restriction & 5 & 6 & 0.42 \\
Other & 55 & & 0.11
\end{tabular}

age at delivery (OR 1.36, 95\% CI 1.01 - 1.81) and need for prostaglandin gel before oxytocin (OR 1.97, 95\% CI 1.27 - 3.04), but not with type of oxytocin protocol $(\mathrm{P}=$ $0.77)$.

Our study, with 399 low-dose and 89 high-dose women, was powered to provide an $80 \%$ chance of obtaining significance (at $\mathrm{P}<0.05$ ) for a true difference of 7 percentage-points in adverse neonatal outcome rates between the two groups.

The admission-to-delivery interval was slightly but significantly shorter for the high-dose group than for the low-dose group (median interval $=11.7$ hours and 14.3 hours, respectively, $\mathrm{P}<0.026$ ) (Figure 1).

\section{DISCUSSION}

We have found that a low-dose protocol for oxytocin infusion for induction of labor is not associated with differences in rates of cesarean section or adverse neonatal outcome, but with significantly longer admission-to- 
Table 3. Univariate analysis of predictors of adverse neonatal events.

\begin{tabular}{cccc}
\hline & No adverse events (n= 535) & Adverse events (n=9) & P value \\
\hline Maternal age (years) & $29.7 \pm 5.8$ & $30.6 \pm 5.3$ & 0.64 \\
Gestational age (weeks) & $40.0 \pm 0.7$ & $39.8 \pm 0.8$ & 0.41 \\
Multiparity & $257(48 \%)$ & $1(11 \%)$ & 0.03 \\
Prostaglandin gel before oxytocin & $150(28 \%)$ & $4(44 \%)$ & 0.28 \\
Low-dose oxytocin protocol & $442(83 \%)$ & $9(100 \%)$ & 0.37 \\
Anesthesia in labor & $460(86 \%)$ & $9(100 \%)$ & 0.62 \\
Artificial rupture of membranes & $387 / 530(73 \%)$ & $8(89 \%)$ & 0.46 \\
Meconium in labor & $119 / 524(23 \%)$ & $1(11 \%)$ & 0.69 \\
Terbutaline for tachysystole & $9(2 \%)$ & $1(11 \%)$ & 0.16 \\
Cesarean delivery & $143(27 \%)$ & $6(67 \%)$ & 0.01 \\
Birth weight (grams) & $3551 \pm 411$ & $3654 \pm 351$ & 0.46 \\
\hline
\end{tabular}

Table 4. Univariate analysis of predictors of cesarean delivery.

\begin{tabular}{cccc}
\hline & Vaginal (n= 395) & Cesarean (n=149) & P value \\
\hline Maternal age (years) & $29.9 \pm 6.0$ & $29.0 \pm 5.6$ & 0.08 \\
Gestational age (weeks) & $39.9 \pm 0.7$ & $40.2 \pm 0.8$ & 0.001 \\
Multiparity & $232(59 \%)$ & $27(18 \%)$ & $<0.001$ \\
Prostaglandin gel before oxytocin & $91(23 \%)$ & $63(42 \%)$ & $<0.001$ \\
Low-dose oxytocin protocol & $328(83 \%)$ & $123(83 \%)$ & 0.89 \\
Anesthesia in labor & $341(86 \%)$ & $128(86 \%)$ & 0.90 \\
Artificial rupture of membranes & $284(72 \%)$ & $411(74 \%)$ & 0.58 \\
Meconium in labor & $76 / 386(19 \%)$ & $3603 \pm 451$ & 0.01 \\
Birth weight (grams) & $3534 \pm 392$ & & 0.08
\end{tabular}

delivery interval. Our results should be taken in the context of the available evidence from published randomized clinical trials on different oxytocin dose regimens. On the issue of fetal and maternal safety, all published trials have found no significant difference in rate of adverse neonatal outcome between low-dose and high-dose regimens for labor induction [5-16]. Moreover, in all trials but one (5) the cesarean section rate was not significantly affected by the dosing regimens.

More controversial is the effect of different oxytocin protocols on induction-to-delivery time. A significant shortening (about 2 hours) in duration of labor with the use of a high-dose regimen was reported by the only double-blinded randomized clinical trial on the subject [3] as well as by several randomized clinical trials [6-9, 11,12]. At variance with these results, other randomized trials did not find a significant difference in duration of labor between two dosing regimen groups [5,10,13-16].
Given such controversy, it is not surprising that a recent systematic review on the subject concluded that more research was needed to determine the benefits and harms of such induction method [17]. Our results of a significantly shorter admission-to-delivery interval in the high-dose group (on average 2.6 hours shorter than in the low-dose oxytocin group) are therefore relevant. However the difference we noted corresponded to only approximately $5 \%$ of the average interval duration in the study population. The significance of this finding is further mitigated by the lack of information on several variables which may affect the interval admission-to-delivery (e.g. Bishop score on admission), as well as by lack of information on duration of first stage of labor. These findings could be interpreted as to suggest that the use of a low-dose oxytocin protocol for labor induction may be preferable, given the unpredictable therapeutic index of oxytocin as well as the known dose-related 


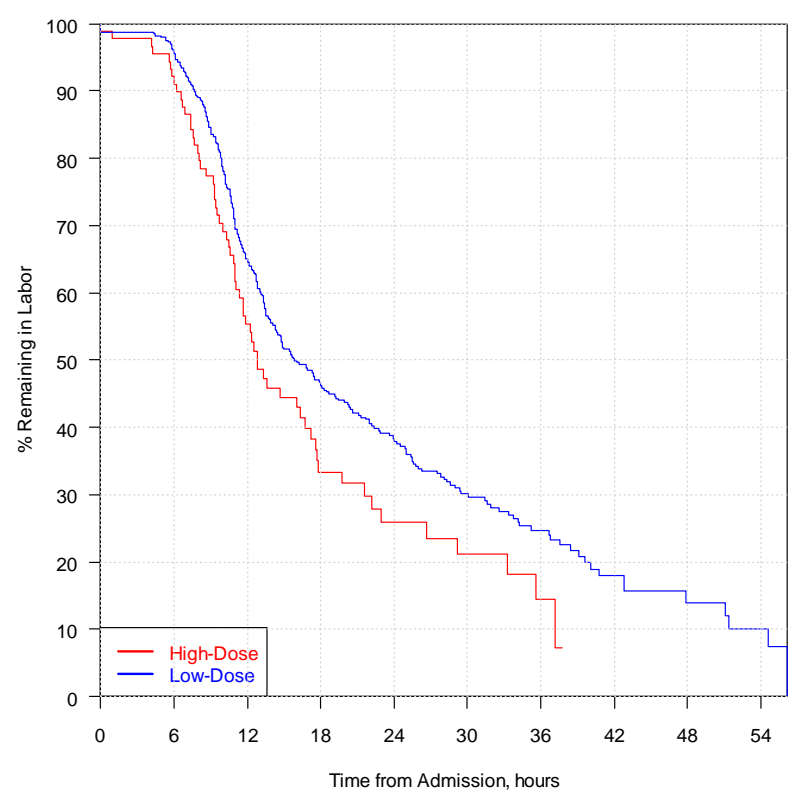

Figure 1. Kaplan-Meier graph of the admission-to-delivery interval in relation to oxytocin protocol.

effects on uterine activity, which mediates the detrimental effects of this drug [18].

The strengths of our study are the large number of patients and the strict adherence to the 2 oxytocin protocols. Moreover, choice of either protocol of oxytocin infusion was largely dictated less by patient characteristics than by the individual physician preference, thus minimizing the risk of selection biases, as witnessed by the similar population characteristics and indications for induction of labor in the two groups.

Limitations of our study are related to the methods of data collection (retrospective cohort study), which did not allow to record certain confounders (e.g. Bishop score on admission and body mass index), duration of active phase of labor, and rates of certain complications (e.g. chorioamnionitis). Moreover, management of labor and delivery other than it pertained to oxytocin infusion (e.g. timing of amniotomy and epidural placement) was left to the discretion of any of the 30 managing obstetricians and midwives. Thus it is possible that the 2 oxytocin protocol groups differed for variables other than those recorded in the database.

Our study does not address the optimal dosage of oxytocin for labor induction. Oxytocin should be titrated to the lowest dose compatible with appropriate uterine activity. Based on the facts that a steady state after oxytocin initiation or dose change occurs in approximately 40 minutes, at which time maximal contractile response is noted, that the therapeutic index of oxytocin is unpredictable, and that an infusion rate of $4-6 \mathrm{mU} / \mathrm{min}$ achieves serum levels corresponding to the spontaneous level of oxytocin during the first stage of labor, it has been sug- gested that a protocol with even lower oxytocin dosage than ours be adopted for labor induction [18]. According to such protocol, initial dose would be $1-2 \mathrm{mU} / \mathrm{min}$, with increases by $2 \mathrm{mU} / \mathrm{min}$ every 45 minutes up to a maximum dose of $16 \mathrm{mU} / \mathrm{min}$.

\section{REFERENCES}

[1] American College of Obstetricians and Gynecologists (2009) Induction of labor. ACOG practice bulletin ${ }^{\#} 107$. Obstetrics \& Gynecology, 114, 386-397. doi:10.1097/AOG.0b013e3181b48ef5

[2] Wei, S.Q., Luo, Z.C., Qi, H.P., Xu, H. and Fraser, W.D. (2010) High-dose vs low-dose oxytocin for labor augmentation: A systematic review. American Journal of $\mathrm{Ob}$ stetrics \& Gynecology, 203, 296-304. doi:10.1016/j.ajog.2010.03.007

[3] Merrill, D.C. and Zlatnik, F.J. (1999) Randomized, double-masked comparison of oxytocin dosage in induction and augmentation of labor. Obstetrics \& Gynecology, 94, 455-463. doi:10.1016/S0029-7844(99)00338-5

[4] Hayes, E.J. and Weinstein, L. (2008) Improving patient safety and uniformity of care by a standardized regimen for the use of oxytocin. American Journal of Obstetrics \& Gynecology, 198, 622.e1-622.e7.

[5] Mercer, B., Pilgrim, P. and Sibai, B. (1991) Labor induction with continuous low-dose oxytocin infusion: A randomized trial. Obstetrics \& Gynecology, 77, 659-663.

[6] Satin, A.J., Hankins, G.D. and Yeomans, E.R. (1991) A prospective study of two dosing regimens of oxytocin for the induction of labor in patients with unfavorable cervices. American Journal of Obstetrics \& Gynecology, 165, 980-984.

[7] Muller, P.R., Stubbs, T.M. and Laurent, S.L. (1992) A prospective randomized trial comparing two oxytocin induction protocols. American Journal of Obstetrics \& Gynecology, 167, 373-381.

[8] Merrill, D.C. and Zlatnik, F.J. (1999) Randomized, double-masked comparison of oxytocin dosage in induction and augmentation of labor. Obstetrics \& Gynecology, 94, 455-463. doi:10.1016/S0029-7844(99)00338-5

[9] Toaff, M.E., Hezroni, J. and Toaff, R. (1978) Induction of labour by pharmacological and physiological doses of intravenous oxytocin. British Journal of Obstetrics and Gynaecology, 85, 101-108. doi:10.1111/j.1471-0528.1978.tb10461.x

[10] Hourvitz, A., Alcalay, M., Korach, J., Lusky, A., Barkai, G. and Seidman, D.S. (1996) A prospective study of highversus low-dose oxytocin for induction of labor. Acta Obstetriccia Gynecologica Scandinavica, 75, 636-641. doi:10.3109/00016349609054688

[11] Orhue, A.A.E. (1993) A randomized trial of 30-min and 15-min oxytocin infusion regimen for induction of labor at term in women of low parity. International Journal of Gynaecology \& Obstetrics, 40, 219-225. doi:10.1016/0020-7292(93)90834-J

[12] Orhue, A.A.E. (1994) Incremental increases in oxytocin 
infusion regimens for induction of labor at term in primigravidas: A randomized controlled trial. Obstetrics \& Gynecology, 83, 229-233.

[13] Blakemre, K.J., Qin, N.G., Petrie, R.H., et al. (1990) A prospective comparison of hourly and quarter-hourly oxytocin dose increase intervals for the induction of labor at term. Obstetrics \& Gynecology, 75, 757-761.

[14] Chua, S., Arulkumaran, S., Kurup, A., et al. (1991) Oxytocin titration for induction of labour: A prospective randomized study of 15 versus 30 minute dose increment schedules. The Australian and New Zealand Journal of Obstetrics and Gynaecology, 32, 134-137. doi:10.1111/j.1479-828X.1991.tb01801.x

[15] Lazor, L.Z., Phillipson, E.H., Ingardia, C.J., et al. (1993) A randomized comparison of 15- and 40-minute dosing protocols for labor augmentation and induction. Obstetrics \& Gynecology, 82, 1009-1012.

[16] Goni, S., Sawhney, H. and Gopalan, S. (1995) Oxytocin induction of abor: A comparison of 20- and 60-min dose increment levels. International Journal of Gynaecology \& Obstetrics, 48, 31-36. doi:10.1016/0020-7292(94)02249-6

[17] Mozurkewich, E.L., Chilimigras, J.L., Berman, D.R., Perni, U.C., Romero, V.C., King, V.J. and Keeton, K.L. (2011) Methods of induction of labour: A systematic review. BMC Pregnancy and Childbirth, 11, 84. doi:10.1186/1471-2393-11-84

[18] Clark, S.L., Simpson, K.R., Knox, G.E. and Garite, T.J. (2009) Oxytocin: New perspectives on an old drug. American Journal of Obstetrics \& Gynecology, 200, 35e1-35e6. 